\title{
Diagnosis of elevated intracranial pressure in critically ill adults: systematic review and meta-analysis
}

\author{
Shannon M Fernando, ${ }^{1,2}$ Alexandre Tran, ${ }^{3,4}$ Wei Cheng, ${ }^{5}$ Bram Rochwerg, ${ }^{6,7}$ Monica Taljaard, 3,5 \\ Kwadwo Kyeremanteng, ${ }^{1,5}$ Shane W English, ${ }^{1,3,5}$ Mypinder S Sekhon, ${ }^{8}$ Donald E G Griesdale, $, 8,10$ \\ Dar Dowlatshahi, ${ }^{3,5,11}$ Victoria A McCredie, ${ }^{12,13}$ Eelco F M Wijdicks, ${ }^{14}$ Saleh A Almenawer, ${ }^{15}$ \\ Kenji Inaba, ${ }^{16}$ Venkatakrishna Rajajee, ${ }^{17,18}$ Jeffrey J Perry ${ }^{2,3,5}$
}

For numbered affiliations see end of the article.

Correspondence to:

SM Fernando,

Department of Emergency

Medicine and Department

of Critical Care Medicine,

The Ottawa Hospital, Civic

Campus, 1053 Carling Avenue,

Ottawa, ON K1Y 4E9, Canada

sfernando@qmed.ca (or@

shanfernands on Twitter;

ORCID 0000-0003-4549-4289)

Additional material is published online only. To view please visit

the journal online.

Cite this as: BMJ 2019;366:14225 http://dx.doi.org/10.1136/bmj.l4225

Accepted: 30 May 2019

\section{ABSTRACT}

OBJECTIVES

To summarise and compare the accuracy of physical examination, computed tomography (CT), sonography of the optic nerve sheath diameter (ONSD), and transcranial Doppler pulsatility index (TCD-PI) for the diagnosis of elevated intracranial pressure (ICP) in critically ill patients.

DESIGN

Systematic review and meta-analysis.

DATA SOURCES

Six databases, including Medline, EMBASE, and

PubMed, from inception to 1 September 2018.

\section{STUDY SELECTION CRITERIA}

English language studies investigating accuracy of physical examination, imaging, or non-invasive tests among critically ill patients. The reference standard was ICP of $20 \mathrm{~mm} \mathrm{Hg}$ or more using invasive ICP monitoring, or intraoperative diagnosis of raised ICP.

DATA EXTRACTION

Two reviewers independently extracted data and assessed study quality using the quality assessment of diagnostic accuracy studies tool. Summary estimates were generated using a hierarchical summary receiver operating characteristic (ROC) model.

RESULTS

40 studies $(n=5123)$ were included. Of physical examination signs, pooled sensitivity and specificity for increased ICP were $28.2 \%$ (95\% confidence

\section{WHAT IS ALREADY KNOWN ON THIS TOPIC}

Elevated intracranial pressure is a complication of brain injury, including traumatic brain injury, subarachnoid haemorrhage, and intracerebral haemorrhage; left untreated, the condition can lead to cerebral ischaemia, brain herniation, and death

Definitive diagnosis requires placement of an invasive monitor, although this method is associated with complications (including haemorrhage and infection) and is not available in all settings

Therefore, clinicians often have to rely on non-invasive diagnostic tests, but the accuracy of these tests is unknown

\section{WHAT THIS STUDY ADDS}

Independent physical examination findings (pupillary dilation, posturing, decreased level of consciousness), imaging (compression of basal cisterns, midline shift), and non-invasive tests had poor accuracy for elevated intracranial pressure

As such, these tests should not be used independently to rule out the condition High suspicion of elevated intracranial pressure could necessitate treatment and transfer to centres capable of invasive monitor placement interval $16.0 \%$ to $44.8 \%)$ and $85.9 \%$ (74.9\% to $92.5 \%)$ for pupillary dilation, respectively; $54.3 \%$ (36.6\% to $71.0 \%$ ) and $63.6 \%$ (46.5\% to $77.8 \%)$ for posturing; and $75.8 \%$ (62.4\% to $85.5 \%)$ and $39.9 \%$ (26.9\% to $54.5 \%)$ for Glasgow coma scale of 8 or less. Among CT findings, sensitivity and specificity were $85.9 \%$ (58.0\% to $96.4 \%$ ) and $61.0 \%$ ( $29.1 \%$ to $85.6 \%$ ) for compression of basal cisterns, respectively; $80.9 \%$ (64.3\% to $90.9 \%$ ) and $42.7 \%$ (24.0\% to $63.7 \%$ ) for any midline shift; and $20.7 \%$ (13.0\% to $31.3 \%)$ and $89.2 \%(77.5 \%$ to $95.2 \%)$ for midline shift of at least $10 \mathrm{~mm}$. The pooled area under the ROC (AUROC) curve for ONSD sonography was 0.94 (0.91 to 0.96). Patient level data from studies using TCD-PI showed poor performance for detecting raised ICP (AUROC for individual studies ranging from 0.55 to 0.72 ).

\section{CONCLUSIONS}

Absence of any one physical examination feature is not sufficient to rule out elevated ICP. Substantial midline shift could suggest elevated ICP, but the absence of shift cannot rule it out. ONSD sonography might have use, but further studies are needed. Suspicion of elevated ICP could necessitate treatment and transfer, regardless of individual non-invasive tests.

\section{REGISTRATION}

PROSPERO CRD42018105642.

\section{Introduction}

Elevated intracranial pressure (ICP) is a commonly encountered complication of brain injury, ${ }^{1}$ and can result in spatial compression, distortion of compartments, and reduced cerebral perfusion pressure. Left untreated, elevated ICP can lead to cerebral ischaemia, brain herniation, and death. Invasive monitoring is the reference standard for measuring ICP, ${ }^{23}$ and sustained values of $20 \mathrm{~mm} \mathrm{Hg}$ or more have been associated with worse outcomes following traumatic brain injury, subarachnoid haemorrhage, intracerebral haemorrhage, and other conditions. ${ }^{4-7}$ Therefore, among critically ill patients, considerable attention must be given to monitoring for this possibility. However, the use of ICP monitoring varies substantially worldwide. ${ }^{8}$

Several clinical practice guidelines indicate that invasive ICP monitoring should be considered in patients in whom there is concern for elevated pressures, or impaired cerebral perfusion. ${ }^{9-11}$ However, invasive ICP monitoring is not available in all settings (particularly in emergency departments, rural, or resource poor settings) where immediate treatment for elevated ICP might be 
required $^{12}$; in most centres, only neurosurgeons are trained in ICP monitor insertion. ${ }^{13}$ Furthermore, the insertion of an ICP monitor is an invasive procedure, and could result in several important complications, including haemorrhage and infection. ${ }^{1415}$

As a result, clinicians often use a variety of noninvasive methods to detect raised ICP, ${ }^{16} 17$ including physical examination and computed tomography (CT) findings, and their presence is often described as indication for invasive monitoring. ${ }^{9-11}$ Despite the widespread use of these signs, their diagnostic accuracy for detection of elevated ICP and their correlation with invasive ICP measurement are unknown. Other novel modalities have been suggested for non-invasive measurement of ICP. In a growing body of literature, researchers have investigated the use of sonography of the optic nerve sheath diameter (ONSD) and the use of metrics based on transcranial Doppler (TCD), such as the pulsatility index (TCD-PI). ${ }^{18} 19$ Given the potential of these bedside tools, better understanding of their diagnostic accuracy is necessary. We conducted a systematic review and meta-analysis with the primary objective of obtaining summary estimates of diagnostic performance (including sensitivity and specificity) of physical examination findings, CT, ONSD sonography, and TCD for the diagnosis of elevated ICP in critically ill adult patients.

\section{Methods}

We structured this systematic review according to PRISMA (preferred reporting items for systematic reviews and meta-analyses) guidelines for diagnostic

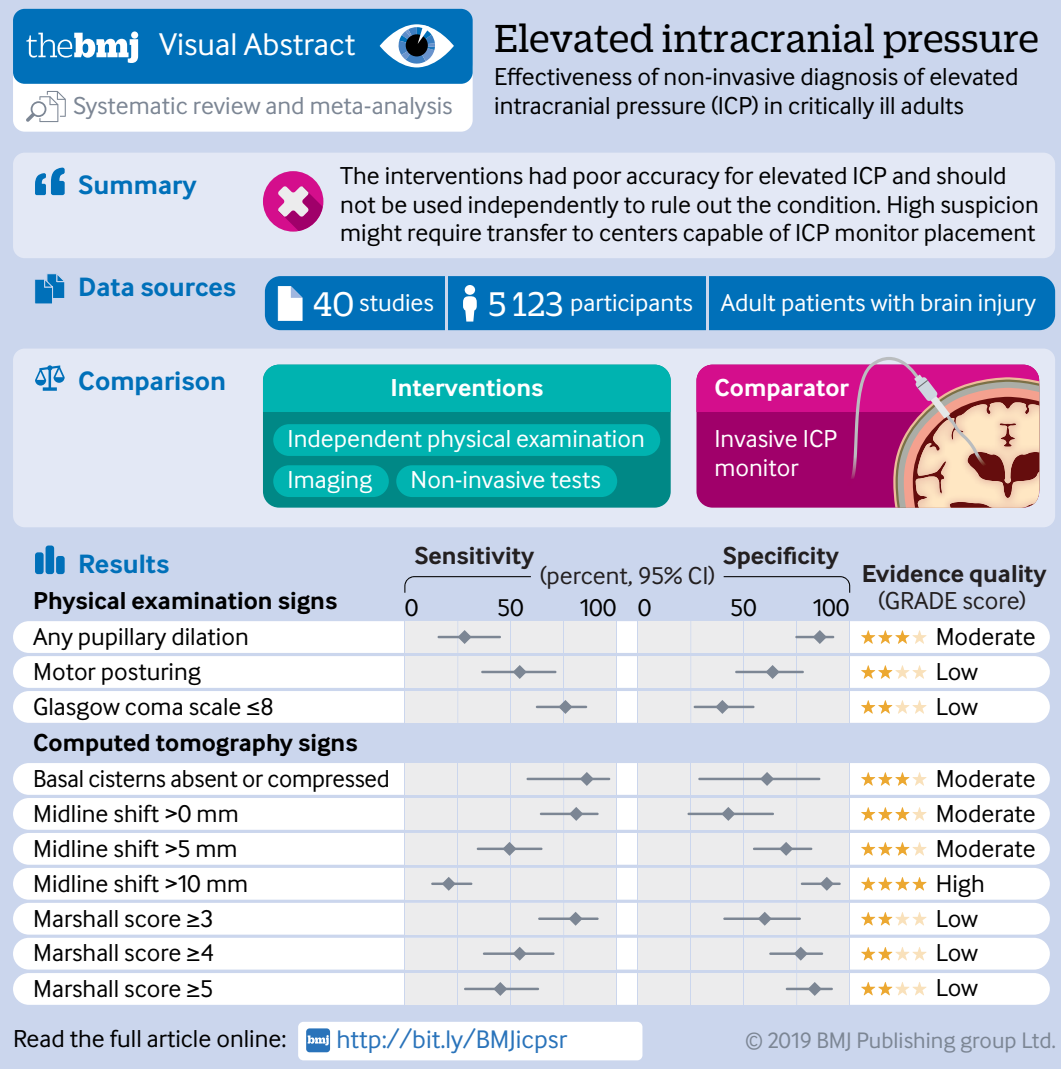

test accuracy, ${ }^{20} 21$ the Cochrane handbook for diagnostic test accuracy, ${ }^{22}$ and existing guidelines for reviews of diagnostic accuracy. ${ }^{23}$ The study protocol was registered with the PROSPERO registry (CRD42018105642).

\section{Search strategy}

We searched six databases (Medline, PubMed, EMBASE, Scopus, Web of Science, and the Cochrane Database of Systematic Reviews) from inception to 1 September 2018. An experienced health sciences librarian assisted in the development of the search strategy. The search was conducted using the terms "intracranial pressure" and "intracranial hypertension" (search strategy shown in supplemental figure 1). We used the Science Citation Index to retrieve reports citing the relevant articles identified from our search. We conducted further surveillance searches using the related articles feature. ${ }^{24}$

\section{Study selection}

We included all English language full text articles describing retrospective and prospective observational studies, and randomised controlled trials. We included studies meeting the following criteria: enrolled adult patients ( $\geq 16$ years); conducted in the emergency department or intensive care unit; and evaluated the test characteristics of physical examination findings, CT, ONSD (measured $3 \mathrm{~mm}$ behind the globe) sonography, or TCD for the diagnosis of elevated ICP. Diagnosis of elevated ICP (reference standard) was defined by any of the following outcomes: invasive ICP monitor with a pressure reading of $20 \mathrm{~mm} \mathrm{Hg}$ or more, or craniotomy with operative diagnosis of elevated ICP. We excluded case reports, case series, animal studies, and paediatric studies. Included studies were required to have a $2 \times 2$ table of true positive, false negative, true negative, and false positive counts, either extracted from the original article or calculated from other reported information. We also excluded studies where the authors had indicated clinically significant latency (defined as $\geq 1$ hour) between the diagnostic test and the measurement of ICP by invasive ICP monitoring, or if the diagnostic test was conducted after ICP measurement. We emailed authors directly if these values could not be obtained from publications. If the corresponding author did not respond after three attempts, the study was excluded.

We screened studies using Covidence (Melbourne, Australia). In phase one, two reviewers (SMF and AT) independently screened the titles and abstracts of all identified studies. In phase two, the same two reviewers independently assessed full texts of the selected articles from phase one. Disagreements were resolved by consensus.

\section{Data extraction}

One investigator (SMF) collected the following variables from included articles: author information, year of publication, study design, eligibility criteria, and number of patients. We used a predesigned 
data extraction sheet (supplemental table 1). Two investigators (SMF and AT) independently collected the true positive, false positive, false negative, and true negative counts. Disagreements were resolved through consensus. All extracted data were verified by a third investigator (WC).

\section{Transcranial Doppler indices}

In studies investigating the accuracy of TCD-PI, multiple TCD-PI values have been taken from each patient. Therefore, for analysis of TCD-PI, we contacted authors to obtain patient level data. For each patient, we asked for all relevant TCD-PI readings and their corresponding invasive ICP measurement. Receiver operating characteristic curves were generated for each study, and were plotted to determine the appropriateness of pooling the data. Area under the ROC curve (AUROC) for detection of elevated ICP was generated for each study. We also evaluated the AUROC of TCD arterial blood pressure (TCD-ABP) methods, including TCD flow velocities (ICPtcd), ${ }^{25}$ and the socalled black box mathematical model. ${ }^{26}$ TCD-ABP methods use changes in cerebrovascular dynamics and non-quantitative cerebral blood flow measures to mathematically estimate ICP.

\section{Quality assessment}

Two reviewers (SMF and AT) independently assessed the risk of bias of the included studies, using the quality assessment of diagnostic accuracy studies (QUADAS-2) tool. ${ }^{27}$ QUADAS-2 assesses four potential areas for bias and applicability of the research question:

- Patient selection: potential risk of bias noted if the evidence indicated verification bias (that is, the reference standard was applied on the basis of the index test)

- Index test: potential risk of bias noted if the index test results were interpreted without explicit blinding to reference standard

- $\quad$ Reference standard: potential risk of bias noted if the reference standard could misclassify the target condition

- $\quad$ Flow and timing: potential risk of bias noted if not all patients had the diagnostic test applied using the same criteria, if the diagnostic test was calculated at an inappropriate time interval before definitive ICP measurement, or if patients were inappropriately excluded.

Studies found to have potential risk of bias for any of these domains were judged as having high risk of bias overall.

\section{Evidence synthesis}

For physical examination and CT findings, we presented individual study results graphically by plotting sensitivity and specificity estimates on one dimensional forest plots (ordered by sensitivity) as well as on the ROC space, to visually assess for heterogeneity. To pool results, we applied the hierarchical summary
ROC model, ${ }^{28}$ and obtained summary point estimates of the pairs of sensitivity and specificity, as well as diagnostic odds ratios and likelihood ratios, with their 95\% confidence intervals. Summary estimates of test accuracy were plotted in the ROC space together with the summary ROC curve. We conducted the analyses using MetaDAS (version 1.3), ${ }^{29}$ as recommended by the Cochrane handbook for systematic review of diagnostic test accuracy. ${ }^{22}$ We conducted predefined sensitivity analyses after excluding studies judged to have potential risk of bias.

Because the diagnostic accuracy of ONSD sonography for prediction of elevated ICP relies on the cutoff threshold of continuous ONSD values, bivariate metaanalysis based on the pair of sensitivity and specificity at the optimal cutoff value from each study might yield overestimated pooled estimates. The AUROC estimates and the corresponding confidence intervals declared in the original articles were meta-analysed by the Dersimonian-Laird random effects model ${ }^{30}$ with Open Meta-Analyst. $^{31}$

We assessed the overall certainty in pooled diagnostic effect estimates using the GRADE (grading of recommendations, assessments, development, and evaluation) approach. ${ }^{32} 33$ The overall confidence in effect estimates was categorised as high, moderate, low, or very low. A GRADE evidence profile was created for each parameter by the guideline development tool (gradepro.org).

\section{Patient and public involvement}

No patients were involved in the definition of the research question, the outcome measures, interpretation of results, or manuscript creation. Where possible, the results of this meta-analysis will be disseminated to individual patients and families by the study investigators.

\section{Results}

\section{Search results}

We identified 3779 citations (fig 1). Following the removal of duplicates, 2570 studies were screened, and 47 studies underwent full text review. We included 40 studies in the meta-analysis, ${ }^{34-73}$ with a total of 5123 patients.

\section{Study characteristics}

Study characteristics are displayed in table 1, with detailed review in supplemental table 2. Of the 40 studies included, $17(47.9 \%(n=2456)$ of patients $)$ were from North America, $11(40.0 \%(n=2071))$ were from Europe, and eight $(11.4 \%(n=586))$ were from Asia. With regards to year of publication, $90.4 \%(n=4633)$ of patients were taken from studies published since 2000, with $71.8 \%(n=3679)$ coming from studies published since 2010. The most common clinical conditions were traumatic brain injury $(64.5 \% \quad(n=3304)$ of patients) $3436394045505356575864-71$ and subarachnoid haemorrhage $(14.3 \%(n=731)) .^{445572}$ Studies of mixed populations of primary brain injury accounted for 


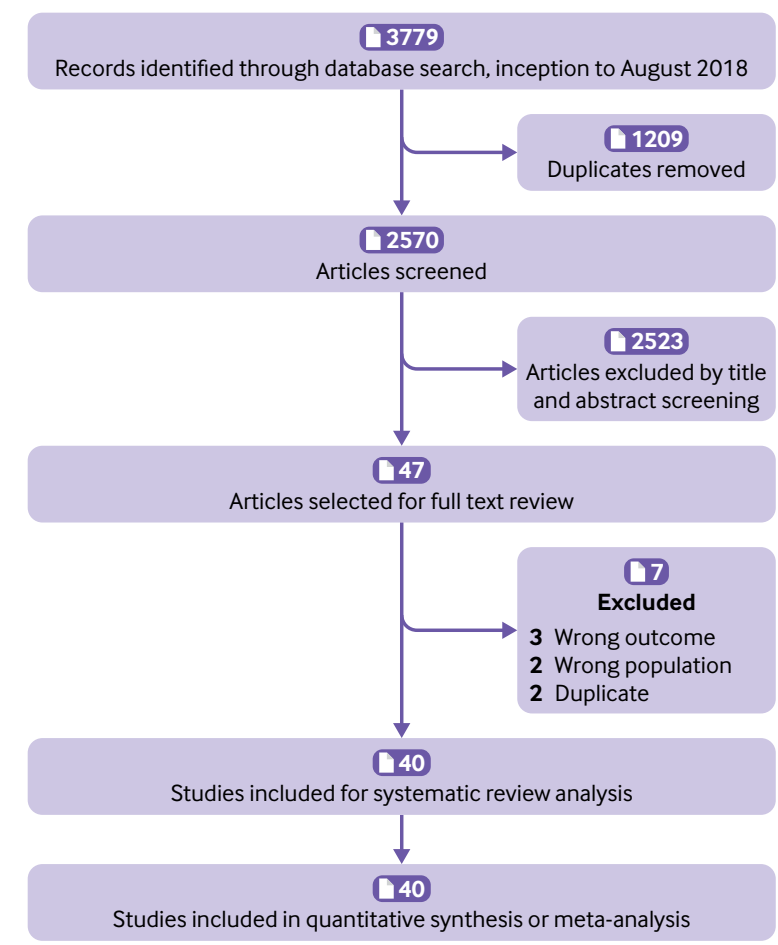

Fig 1 | Flowchart summarising evidence search and study selection

18.8\% (n=961) of patients. ${ }^{38} 42434649515254596063$ Two studies exclusively looked at patients with intracerebral haemorrhage, ${ }^{4148}$ two enrolled patients with hepatic failure, ${ }^{37} 61$ and one assessed patients with ischaemic stroke. ${ }^{47}$

\section{Quality assessment}

Quality assessments are summarised in supplemental figure 2. Because evidence of elevated ICP noted during neurosurgery could misclassify the target

\begin{tabular}{|c|c|c|}
\hline Description & No (\%) of studies & No (\%) of patients \\
\hline \multicolumn{3}{|l|}{ Continent of study } \\
\hline North America & $17(42.5)$ & $2456(47.9)$ \\
\hline Europe & $14(35.0)$ & $2071(40.0)$ \\
\hline Asia & $8(20.0)$ & $586(11.4)$ \\
\hline South America & $1(2.5)$ & $10(0.2)$ \\
\hline \multicolumn{3}{|l|}{ Year of publication } \\
\hline $1975-79$ & $2(5.0)$ & $193(3.7)$ \\
\hline 1980-89 & $8(20.0)$ & $230(4.5)$ \\
\hline 1990-99 & $2(5.0)$ & $67(1.3)$ \\
\hline 2000-09 & $8(20.0)$ & $954(18.6)$ \\
\hline $2010-18$ & $20(50.0)$ & $3679(71.8)$ \\
\hline \multicolumn{3}{|l|}{ Study design } \\
\hline Prospective cohort & $24(60.0)$ & $2772(54.1)$ \\
\hline Retrospective cohort & $15(37.5)$ & $1986(38.8)$ \\
\hline Randomised controlled trial & $1(2.5)$ & $365(7.1)$ \\
\hline \multicolumn{3}{|l|}{ Population } \\
\hline Mixed & $12(30.0)$ & $961(18.8)$ \\
\hline Traumatic brain injury & $20(50.0)$ & $3304(64.5)$ \\
\hline Subarachnoid haemorrhage & $3(7.5)$ & $731(14.3)$ \\
\hline Intracerebral haemorrhage & $2(5.0)$ & $67(1.3)$ \\
\hline Ischaemic stroke & $1(2.5)$ & $25(0.5)$ \\
\hline Hepatic failure & $2(5.0)$ & $35(0.7)$ \\
\hline
\end{tabular}

condition of elevated ICP, the four studies that used this surgery as a reference standard were considered to have potentially high risk of bias. ${ }^{50576871}$ One study used an epidural pressure monitor for the diagnosis of elevated ICP in critically ill patients, and was also considered to have potentially high risk of bias. ${ }^{37}$ Two other studies were considered to have potentially high risk of bias, because assessors were not blinded to ICP monitor results. ${ }^{43} 52$

\section{Results of synthesis}

Summary estimates of all diagnostic accuracy measures for each physical examination finding and CT finding are displayed in table 2. All summary estimates described are pooled values. GRADE evidence profiles are shown in supplemental tables 3-12.

\section{Physical examination}

Only three physical examination findings had an adequate number of relevant studies for meta-analysis: pupillary dilation, $^{34} 4550-5356586871$ motor posturing (defined by Glasgow coma scale motor score $\leq 3),{ }^{374445535658}$ and decreased level of consciousness (defined by total Glasgow coma scale $\leq 8))^{34415055575861636572}$ Their forest plots and hierarchical summary ROC curves are shown in supplemental figures 3-5. Presence of pupillary dilation had a sensitivity of $28.2 \%$ (95\% confidence interval $16.0 \%$ to $44.8 \%$ ) and specificity of $85.9 \%$ (74.9\% to $92.5 \%$ ) for the diagnosis of elevated ICP (moderate certainty; table 2). Presence of motor posturing had a sensitivity of $54.3 \%$ (36.6\% to $71.0 \%)$ and specificity of $63.6 \%$ ( $46.5 \%$ to $77.8 \%$ ) for the diagnosis of elevated ICP (low certainty). Finally, a decreased level of consciousness had a sensitivity of $75.8 \%(62.4 \%$ to $85.5 \%)$ and specificity of $39.9 \%$ (26.9\% to $54.5 \%)$ for the diagnosis of elevated ICP (low certainty).

\section{Computed tomography}

We evaluated multiple CT signs, including absence or compression of basal cisterns, ${ }^{3657616870}$ any midline shift (using either the pineal body or the septum pellucidum as the midline structure), 3942434752576469 midline shift more than $5 \mathrm{~mm},{ }^{394243475257686972}$ midline shift more than $10 \mathrm{~mm},{ }^{3942434748525769}$ and the Marshall classification system ${ }^{74}$ at various thresholds. ${ }^{40} 506371$ However, no included studies evaluated the sensitivity and specificity of a so-called normal CT, with none of the above signs. Forest plots and hierarchical summary ROC curves are shown in supplemental figures 6-12. Pooled sensitivity and specificity by Marshall Class are shown in supplemental figure 13. Absence or compression of basal cisterns on CT had a sensitivity of $85.9 \%$ (95\% confidence interval $58.0 \%$ to $96.4 \%$; table 2) and specificity of $61.0 \%$ (29.1\% to $85.6 \%)$ for the diagnosis of elevated ICP (moderate certainty). Presence of any midline shift on CT had a sensitivity of $80.9 \%(64.3 \%$ to $90.9 \%)$ and specificity of $42.7 \%$ (24.0\% to $63.7 \%$; moderate certainty). Severe midline shift (that is, $>10$ $\mathrm{mm}$ ) had a sensitivity of $20.7 \%$ (13.0\% to $31.3 \%)$ and specificity of $89.2 \%$ ( $77.5 \%$ to $95.2 \%$; high certainty). 


\begin{tabular}{|c|c|c|c|c|c|c|}
\hline & \multirow{2}{*}{$\begin{array}{l}\text { No of patients } \\
\text { (No of cohorts) }\end{array}$} & \multirow{2}{*}{$\begin{array}{l}\text { Sensitivity } \\
(\% ; 95 \% \mathrm{Cl})\end{array}$} & \multirow{2}{*}{$\begin{array}{l}\text { Specificity } \\
(\% ; 95 \% \mathrm{Cl})\end{array}$} & \multirow{2}{*}{$\begin{array}{l}\text { Diagnostic odds ratio } \\
(95 \% \mathrm{Cl})\end{array}$} & \multicolumn{2}{|c|}{ Likelihood ratio $(95 \% \mathrm{Cl})$} \\
\hline & & & & & Positive & Negative \\
\hline \multicolumn{7}{|l|}{ Physical examination signs } \\
\hline Any pupillary dilation & $2126(10)$ & $28.2(16.0$ to 44.8$)$ & 85.9 (74.9 to 92.5$)$ & 2.39 (1.59 to 3.58$)$ & 2.00 (1.44 to 2.78$)$ & $0.84(0.73$ to 0.95$)$ \\
\hline $\begin{array}{l}\text { Motor posturing (Glasgow } \\
\text { coma scale motor score } \leq 3 \text { ) }\end{array}$ & $830(6)$ & 54.3 (36.6 to 71.0$)$ & $63.6(46.5$ to 77.8$)$ & 2.08 (1.40 to 3.09$)$ & $1.49(1.17$ to 1.90$)$ & $0.72(0.57$ to 0.90$)$ \\
\hline Glasgow coma scale $\leq 8$ & $2234(10)$ & $75.8(62.4$ to 85.5$)$ & 39.9 (26.9 to 54.5$)$ & 2.07 (1.29 to 3.32$)$ & $1.26(1.07$ to 1.49$)$ & $0.61(0.43$ to 0.85$)$ \\
\hline \multicolumn{7}{|l|}{ Computed tomography signs } \\
\hline $\begin{array}{l}\text { Basal cisterns absent or } \\
\text { compressed }\end{array}$ & $619(5)$ & 85.9 (58.0 to 96.4$)$ & $61.0(29.1$ to 85.6$)$ & 9.55 (1.56 to 56.61$)$ & $2.20(0.99$ to 4.93$)$ & $0.23(0.06$ to 0.84$)$ \\
\hline Midline shift >0 mm & $627(8)$ & 80.9 (64.3 to 90.9) & $42.7(24.0$ to 63.7$)$ & $3.16(1.43$ to 7.01$)$ & $1.41(1.04$ to 1.91$)$ & $0.45(0.25$ to 0.80$)$ \\
\hline Midline shift $>5 \mathrm{~mm}$ & $832(9)$ & $49.4(34.5$ to 64.4$)$ & 70.0 (54.9 to 81.8$)$ & $2.28(1.26$ to 4.13$)$ & 1.65 (1.13 to 2.41$)$ & $0.72(0.56$ to 0.93$)$ \\
\hline Midline shift >10 mm & $651(8)$ & 20.7 (13.0 to 31.3) & 89.2 (77.5 to 95.2) & $2.16(0.87$ to 5.37$)$ & $1.92(0.87$ to 4.25$)$ & $0.89(0.78$ to 1.01$)$ \\
\hline Marshall score $\geq 3$ & $1316(4)$ & 80.6 (63.5 to 90.9$)$ & $59.9(40.9$ to 76.4$)$ & $6.22(2.55$ to 15.22$)$ & 2.01 (1.32 to 3.07$)$ & $0.32(0.17$ to 0.61$)$ \\
\hline Marshall score $\geq 4$ & $1316(4)$ & $54.2(37.4$ to 70.1$)$ & 76.9 (62.6 to 86.9) & $3.93(1.63$ to 9.50$)$ & $2.34(1.33$ to 4.13$)$ & $0.60(0.41$ to 0.87$)$ \\
\hline Marshall score $\geq 5$ & $1316(4)$ & 45.1 (28.5 to 62.8$)$ & 83.5 (70.4 to 91.5$)$ & $4.15(1.65$ to 10.42$)$ & $2.73(1.40$ to 5.31$)$ & $0.66(0.48$ to 0.91$)$ \\
\hline
\end{tabular}

Sensitivity for elevated ICP decreased from a Marshall Class of at least $3(80.6 \%, 63.5 \%$ to $90.9 \%)$ to at least 5 (45.1\%, 28.5\% to $62.8 \%$; low certainty). Conversely, specificity increased from a Marshall Class of at least 3 $(59.9 \%, 40.9 \%$ to $76.4 \%)$ to a Marshall Class of at least 5 (83.5\%, $70.4 \%$ to $91.5 \%$; low certainty).

\section{Optic nerve sheath diameter}

Figure 2 shows a forest plot of AUROC values for the detection of raised ICP by ONSD sonography. Ten studies provided AUROC values for the detection of elevated ICP in a total of 1035 critically ill patients. 38404649545960636667 The pooled AUROC value was 0.94 (95\% confidence interval $0.91 \%$ to $0.96 \%, \mathrm{I}^{2}=60.9 \%$ ) for detection of elevated ICP with ONSD sonography. Various ONSD thresholds used across studies, along with corresponding sensitivities and specificities, are described in supplemental table 13 and supplemental figure 14.

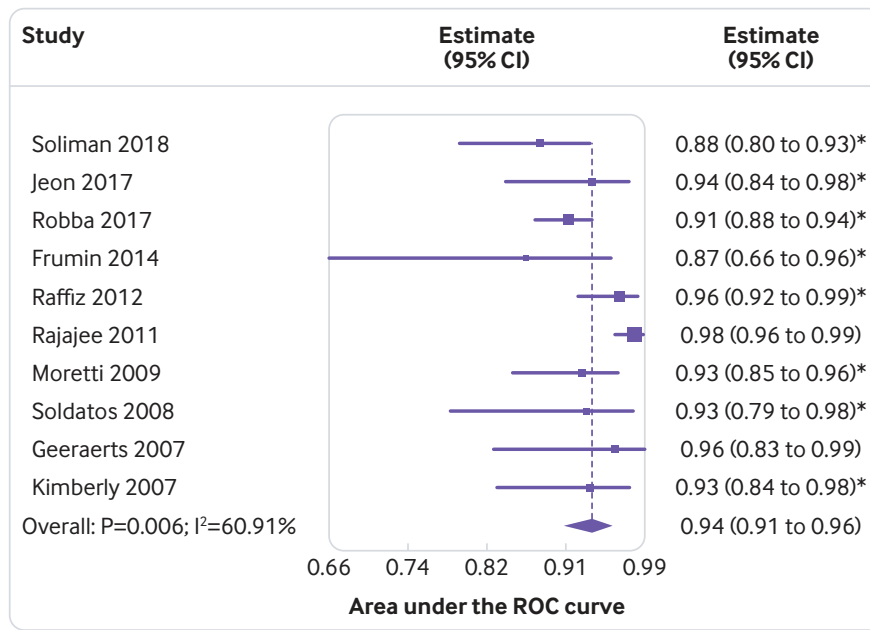

Fig 2 | Pooled area under the ROC curve for diagnostic accuracy of sonography of the optic nerve sheath diameter to detect intracranial pressure of $20 \mathrm{~mm} \mathrm{Hg}$ or more across studies. *Reported upper limit of $95 \%$ confidence interval not symmetrical with the lower limit in the original or logit scale. Therefore, only values with their lower confidence limits were used, and symmetry in the logit scale was assumed for the meta-analysis

\section{Transcranial Doppler indices}

We calculated AUROC values for TCD-PI to detect ICP of $20 \mathrm{~mm} \mathrm{Hg}$ or more within each study using patient level data ${ }^{35616373}$ (794 patients). The ROC curves for individual studies are shown in figure 3, and AUROC values ranged from 0.550 to 0.718 , which suggested that pooling patient level data across studies was not appropriate. Three studies evaluated TCD-ABP methods for detection of ICP of at least $20 \mathrm{~mm} \mathrm{Hg}$ (supplemental figure 15 and supplemental table 14). ${ }^{356162}$ The pooled AUROC value for detection of elevated ICP with combined TCD-ABP methods was 0.85 (95\% confidence interval 0.78 to $0.91, \mathrm{I}^{2}=9.6 \%$ ).

\section{Sensitivity analyses excluding studies with high risk of bias}

Results of our sensitivity analyses, after exclusion of studies deemed to have potential high risk of bias, are shown in supplemental table 15 and supplemental figures 16-22. These results did not affect overall conclusions.

\section{Discussion}

We conducted a systematic review and meta-analyses to investigate the accuracy of non-invasive tests for the diagnosis of elevated ICP in critically ill patients, compared with invasive ICP monitoring. Although several studies have failed to identify an optimal strategy for targeted ICP management, ${ }^{75} 767778$ current guidelines advocate for treatment at an ICP threshold of $20-25 \mathrm{~mm} \mathrm{Hg} .{ }^{9} 79$ With the possible complications of invasive monitoring, non-invasive identification of patients with elevated ICP is of potential benefit. We found that individual physical examination and CT findings, in isolation, were not sufficiently sensitive for the detection of elevated ICP. Studies investigating sonography of the ONSD used many different optimal thresholds for the diagnosis of elevated ICP, with varying degrees of sensitivity and specificity at any specific threshold. TCD-PI had poor accuracy for the diagnosis of elevated ICP, though other TCD-ABP methods show some promise. Taken together, our study summarises the individual accuracy of non-invasive methods for the diagnosis of elevated ICP. 


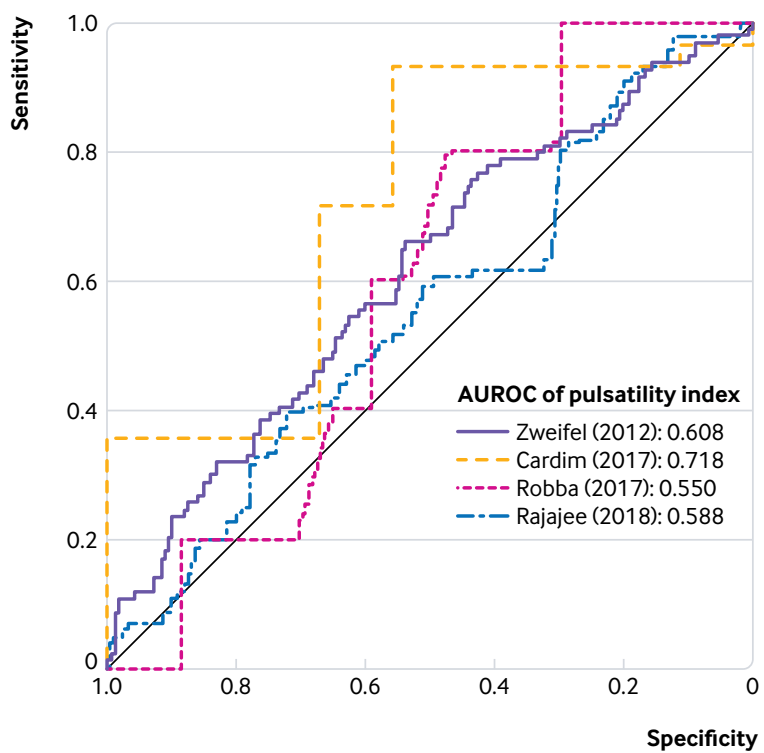

Fig 3 | Generated receiver operating characteristic curves for diagnostic accuracy of transcranial Doppler-pulsatility index for intracranial pressure of $20 \mathrm{~mm} \mathrm{Hg}$ or more, as based on individual patient level data from four studies. $A U R O C=$ area under receiver operating characteristic curve
Furthermore, we initially used a broad reference standard that combined invasive ICP measurement or intraoperative evidence of elevated ICP. Intraoperative assessment could misclassify the target condition, although we did a sensitivity analysis after removing these studies, which did not alter our conclusions. Additionally, prevalence of elevated ICP varied between studies, which allowed for the possibility of spectrum bias. Studies with higher prevalence of elevated ICP could be biased towards prioritising and emphasising tests associated with severe or late disease, as opposed to tests that might be more useful for screening a lower risk population. Finally, the threshold for high ICP at $20 \mathrm{~mm} \mathrm{Hg}$ or higher was an arbitrary choice, because ICP measurement is dynamic and must be interpreted within the clinical context. However, a considerable amount of evidence has linked sustained ICP of $20 \mathrm{~mm}$ $\mathrm{Hg}$ or higher with poor outcomes, and this value was used most consistently in the literature.

\section{Comparison with other studies}

During the initial assessment of patients with brain injury, clinicians usually look for physical examination signs of elevated ICP, including pupillary dilation, motor posturing, and decreased level of consciousness. ${ }^{17}$ Many have advocated for early ICP management in patients with such signs (especially in the emergency department, or when transfer for definitive diagnosis and management might be delayed). ${ }^{12}$ However, certain treatments for high ICP (eg, hyperosmolar treatment) can have adverse effects. ${ }^{80}$ We found that none of these classically described physical examination findings alone was sensitive or specific enough for the diagnosis of elevated ICP. This shortcoming in diagnostic accuracy is best demonstrated by assessing how pre-test probability is influenced by the presence or absence of any one of these signs (supplemental table 16). For a patient with a 50\% pre-test probability of elevated ICP, the presence of pupillary dilation, motor posturing, or decreased level of consciousness increases the post-test probability to $66.6 \%, 59.9 \%$, and $55.8 \%$, respectively. Their absence decreases the post-test probability to $45.5 \%, 41.8 \%$, and $37.8 \%$, respectively. Therefore, the presence of any of these physical signs does not independently indicate elevated ICP. Similarly, absence of any one sign does not adequately rule out elevated ICP. Clinicians without access to any other further methods of testing (eg, in remote or resource poor settings) should not solely rely on these signs to guide initiation of treatment, or the decision to transfer the patient to a more expert centre.

CT findings are thought to have greater reliability for detecting elevated ICP than physical examination, ${ }^{81}$ and many studies use CT as the reference standard for elevated ICP. Compression or effacement of the basal cisterns can occur secondary to increased parenchymal oedema, and has long been thought to be a sensitive indicator of elevated ICP. ${ }^{82} 83$ We found that compression or effacement of basal cisterns had a sensitivity of $85.9 \%$, and a specificity of $61.0 \%$. When evaluated using bayesian principles (supplemental indicate whether reference ICP values from invasive measurement were based on one point in time, or averaged over an interval, and did not describe time of measurement in relation to any initiated treatment. This lack of clarity in reporting could introduce bias in our analyses. 
table 17 ), a patient with a $50 \%$ pre-test probability of elevated ICP still retains a $18.7 \%$ probability despite absence of basal cistern compression or effacement. Therefore, an appreciable number of cases of elevated ICP could be missed if only relying on this sign. Another CT finding that clinicians often consider is midline shift, with worsening shift thought to be associated with higher ICP. $^{81}$ In our review, the presence of any midline shift only had a sensitivity of $80.9 \%$, an important reminder to clinicians that severe oedema can result in elevated ICP, without evidence of shift on CT. Severe midline shift (that is, $>10 \mathrm{~mm}$ ) had a specificity of $89.2 \%$, but in a patient with a pre-test suspicion of increased ICP of $50 \%$, its presence will only increase post-test probability to $65.8 \%$. Finally, we found that Marshall classification was neither sensitive nor specific, regardless of the threshold used.

Given its increasing use in the clinical setting, we evaluated the accuracy of sonography of the ONSD for detection of elevated ICP. ${ }^{84}$ However, the varied thresholds used across studies did not allow meta-analysis of sensitivity and specificity at any threshold in our study. The pooled AUROC did suggest high accuracy, although with moderate statistical heterogeneity. Our findings align with a recent metaanalysis answering the same question, although we included a greater number of studies. ${ }^{85}$ Despite high pooled AUROC, the variability in thresholds (and sensitivity and specificity at any specific threshold) suggests that caution should be exercised in the use of ONSD sonography. Its optimised accuracy varies, and no consensus exists on the optimal ONSD threshold to detect elevated ICP. Furthermore, ONSD sonography is often difficult to perform in patients with clinically significant facial trauma, and contraindicated in patients with suspected globe injury. Therefore, at present, the use of ONSD sonography for the diagnosis of elevated ICP remains unclear.

Finally, we examined accuracy of TCD-PI using patient level data from four studies. None of the individual studies showed good accuracy for detection of raised ICP, suggesting that TCD-PI might not be useful for this purpose. However, investigation of TCD-ABP methods found relatively stronger accuracy among these methods, including TCD flow velocities and the so-called black box mathematical model. Even though both ONSD sonography and TCD-PI might be immediately available in centres where invasive testing is not, their use for the diagnosis of elevated ICP should be used with caution. Although TCD-ABP methods show promise, particularly to exclude elevated ICP, further research is required. At least one multicentre prospective study of TCD-ABP found a systematic overestimation of ICP. ${ }^{62}$

While our findings have obvious value to clinicians who have patients with brain injury, they also have important implications for the development of clinical practice guidelines. ${ }^{86}$ At present, multiple guidelines advocate for invasive monitoring only in patients with concerning physical examination and
CT signs, ${ }^{910}$ which has resulted in the varied use of invasive monitoring worldwide. ${ }^{8}$ This study shows that individual physical examination findings and CT signs are not adequately accurate in the diagnosis of elevated ICP, although we were unable to examine the accuracy of combinations of findings, as found in many current guidelines. Our study suggests that decisions related to the use of monitoring should not simply be restricted to any one specific physical examination or CT criterion, but rather a more comprehensive view should be taken, focusing on patient factors, factors related to the brain injury, as well as clinical signs. ${ }^{87}$ Given the potential role for ICP monitoring to improve outcomes by avoiding further brain injury due to high pressures, understanding its potential breadth of use has important implications in the care of critically ill patients. ${ }^{79}$ For clinicians caring for these patients (particularly in resource limited settings), high suspicion of elevated ICP should prompt consideration of empirical treatment, as well as invasive ICP monitoring, or transfer to a capable centre.

\section{Conclusions and policy implications}

Our systematic review and meta-analyses found that individual physical examination signs were not sufficiently sensitive for the diagnosis of elevated ICP. CT findings (namely, effacement of basal cisterns) had better diagnostic accuracy, but are not readily available in all centres. ONSD sonography could be an accurate method of measuring ICP, but no agreed threshold exists, and the method's accuracy can be influenced by provider expertise. Therefore, providers should exercise caution in interpretation of any findings derived from ONSD sonography. TCD-PI had poor performance, but TCD-ABP methods might be promising for diagnosing elevated ICP, although further validation is required. Given the available evidence, clinicians must take a comprehensive view of patients with primary brain injury, and should consider empirical treatment followed by invasive monitoring (or transfer to a capable centre) if they have any clinical concerns for increased ICP.

\section{AUTHOR AFFILIATIONS}

${ }^{1}$ Division of Critical Care, Department of Medicine, University of Ottawa, Ottawa, ON, Canada

${ }^{2}$ Department of Emergency Medicine, University of Ottawa, Ottawa, ON, Canada

${ }^{3}$ School of Epidemiology and Public Health, University of Ottawa, Ottawa, ON, Canada

${ }^{4}$ Department of Surgery, University of Ottawa, Ottawa, ON, Canada

${ }^{5}$ Clinical Epidemiology Program, Ottawa Hospital Research Institute, Ottawa, ON, Canada

${ }^{6}$ Department of Medicine, Division of Critical Care, McMaster University, Hamilton, ON, Canada

${ }^{7}$ Department of Health Research Methods, Evidence, and Impact, McMaster University, Hamilton, ON, Canada

${ }^{8}$ Department of Medicine, Division of Critical Care Medicine, University of British Columbia, Vancouver, BC, Canada

${ }^{9}$ Centre for Clinical Epidemiology and Evaluation, Vancouver Coastal Health Research Institute, Vancouver, BC, Canada

${ }^{10}$ Department of Anesthesiology, Pharmacology, and Therapeutics, University of British Columbia, Vancouver, BC, Canada 
${ }^{11}$ Divison of Neurology, Department of Medicine, University of Ottawa, Ottawa, ON, Canada

${ }^{12}$ Interdepartmental Division of Critical Care, Department of Medicine, University of Toronto, Toronto, ON, Canada

${ }^{13}$ Toronto Western Hospital, University Health Network, Toronto, ON, Canada

${ }^{14}$ Division of Neurocritical Care and Hospital Neurology, Department of Neurology, Mayo Clinic, Rochester, MN, USA

${ }^{15}$ Division of Neurosurgery, Department of Surgery, McMaster University, Hamilton, ON, Canada

${ }^{16}$ Division of Acute Care Surgery, Department of Surgery, University of Southern California, Los Angeles, CA, USA

${ }^{17}$ Department of Neurology, University of Michigan, Ann Arbor, MI, USA

${ }^{18}$ Department of Neurosurgery, University of Michigan, Ann Arbor, MI, USA

We thank Ian Ball, Danilo Cardim, Nicolas de Riva, Jacob Pace, Chiara Robba, and Christian Zweifel for providing primary data that allowed for completion of meta-analyses.

Contributors: SMF, AT, and JJP conceived the study idea. SMF, AT, WC $B R$, and $J P$ coordinated the systematic review. SMF and AT designed the search strategy, screened abstracts and full texts, acquired the data, and judged risk of bias in the studies. WC performed the data analysis. BR created the GRADE evidence profiles. All authors interpreted the data analysis and critically revised the manuscript. All authors had the opportunity to review the final manuscript, and provided their permission to publish the manuscript. All authors agree to take responsibility for the work. SMF is guarantor. The corresponding author attests that all listed authors meet authorship criteria, and that no others meeting the criteria have been omitted.

Funding: None received.

Competing interests: All authors have completed the ICMJE uniform disclosure form at www.icmje.org/coi_disclosure.pdf and declare: no support from any organisation for the submitted work; no financial relationships with any organisations that might have an interest in the submitted work in the previous three years; no other relationships or activities that could appear to have influenced the submitted work.

Ethics approval: Not applicable.

Data sharing: The Meta-DAS SAS macro (recommended by the Cochrane handbook for systematic reviews of diagnostic test accuracy) is available at https://methods.cochrane.org/sdt/ software-meta-analysis-dta-studies and is also available from the corresponding author.

The lead author affirms that the manuscript is an honest, accurate, and transparent account of the study being reported; that no important aspects of the study have been omitted; and that any discrepancies from the study as planned have been explained.

This is an Open Access article distributed in accordance with the Creative Commons Attribution Non Commercial (CC BY-NC 4.0) license, which permits others to distribute, remix, adapt, build upon this work non-commercially, and license their derivative works on different terms, provided the original work is properly cited and the use is non-commercial. See: http://creativecommons.org/licenses/ by-nc/4.0/.

1 Mollan SP, Spitzer D, Nicholl DJ. Raised intracranial pressure in those presenting with headache. BMJ 2018;363:k3252. doi:10.1136/bmj. k3252

2 Czosnyka M, Smielewski P, Lavinio A, Czosnyka Z, Pickard JD. A synopsis of brain pressures: which? when? are they all useful? Neurol Res 2007;29:672-9. doi:10.1179/016164107×240053

3 Citerio G, Andrews PJ. Intracranial pressure Part two: Clinical applications and technology. Intensive Care Med 2004;30:1882-5. doi:10.1007/s00134-004-2377-3

4 Stocchetti N, Maas Al. Traumatic intracranial hypertension. N Engl/ Med 2014:370:2121-30 doi:10.1056/NEJMra1208708

5 Cahill J, Calvert JW, Zhang JH. Mechanisms of early brain injury after subarachnoid haemorrhage [correction in: / Cereb Blood Flow Metab 2006:26:1463]. J Cereb Blood Flow Metab 2006:26:1341-53. doi:10.1038/sj.jcbfm.9600283

6 Cordonnier C, Demchuk A, Ziai W, Anderson CS. Intracerebral haemorrhage: current approaches to acute management Lancet 2018;392:1257-68. doi:10.1016/S0140-6736(18) 31878-6

7 Czosnyka M, Pickard JD. Monitoring and interpretation of intracranial pressure. / Neurol Neurosurg Psychiatry 2004:75:813-21. doi:10.1136/jnnp.2003.033126
8 Cnossen MC, Huijben JA, van der Jagt M, et al, CENTER-TB investigators. Variation in monitoring and treatment policies for intracranial hypertension in traumatic brain injury: a survey in 66 neurotrauma centers participating in the CENTER-TBI study. Crit Care 2017;21:233. doi:10.1186/s13054-017-1816-9

9 Carney N, Totten AM, O'Reilly C, et al. Guidelines for the management of severe traumatic brain injury. Neurosurgery 2017;80:6-15.

10 Hemphill JC3rd, Greenberg SM, Anderson CS, et al, American Heart Association Stroke Council, Council on Cardiovascular and Stroke Nursing, Council on Clinical Cardiology. Guidelines for the management of spontaneous intracerebral hemorrhage: a guideline for healthcare professionals from the American Heart Association/American Stroke Association. Stroke 2015:46:2032-60. doi:10.1161/STR.0000000000000069

11 Fried HI, Nathan BR, Rowe AS, et al. The insertion and management of external ventricular drains: an evidence-based consensus statement a statement for healthcare professionals from the Neurocritical Care Society. Neurocrit Care 2016;24:61-81. doi:10.1007/s12028-015 0224-8

12 Long B, Koyfman A. Secondary gains: advances in neurotrauma management. Emerg Med Clin North Am 2018;36:107-33. doi:10.1016/i.emc.2017.08.007

13 Ekeh AP, Ilyas S, Saxe JM, et al. Successful placement of intracranial pressure monitors by trauma surgeons. J Trauma Acute Care Surg 2014:76:286-90, discussion 290-1. doi:10.1097/ TA.0000000000000092

14 Holloway KL, Barnes T, Choi S, et al. Ventriculostomy infections: the effect of monitoring duration and catheter exchange in 584 patients. / Neurosurg 1996:85:419-24. doi:10.3171/ ins.1996.85.3.0419

15 Binz DD, Toussaint LG3rd, Friedman JA. Hemorrhagic complications of ventriculostomy placement: a meta-analysis. Neurocrit Care 2009:10:253-6. doi:10.1007/s12028-009-9193-0

16 Kristiansson H, Nissborg E, Bartek JJr, Andresen M, Reinstrup $\mathrm{P}$, Romner B. Measuring elevated intracranial pressure through noninvasive methods: a review of the literature. Neurosurg Anesthesiol 2013;25:372-85. doi:10.1097/ ANA.0b013e31829795ce

17 Rosenberg IB, Shiloh AL, Savel RH, Eisen LA. Non-invasive methods of estimating intracranial pressure. Neurocrit Care 2011;15:599-608. doi:10.1007/s12028-011-9545-4

18 Geeraerts T, Merceron S, Benhamou D, Vigué B, Duranteau J. Noninvasive assessment of intracranial pressure using ocular sonography in neurocritical care patients. Intensive Care Med 2008;34:2062-7. doi:10.1007/s00134-008-1149-x

19 de Riva N, Budohoski KP. Smielewski P, et al. Transcranial Doppler pulsatility index: what it is and what it isn't. Neurocrit Care 2012;17:58-66. doi:10.1007/s12028-012-9672-6

20 Moher D, Liberati A, Tetzlaff |, Altman DG, PRISMA Group. Preferred reporting items for systematic reviews and meta-analyses: the PRISMA statement. BMJ 2009;339:b2535. doi:10.1136/bmj.b2535

21 McInnes MDF, Moher D, Thombs BD, et al, the PRISMA-DTA Group. Preferred Reporting Items for a Systematic Review and Meta-analysis of Diagnostic Test Accuracy Studies: The PRISMA-DTA Statement. JAMA 2018;319:388-96. doi:10.1001/jama.2017.19163

22 Deeks II, Bossuyt PM, Gatsonis C. Cochrane handbook for systematic reviews of diagnostic test accuracy, Version 1.0.0. 2013;http://srdta. cochrane.org/

23 Leeflang MM, Deeks II, Gatsonis C, Bossuyt PM, Cochrane Diagnostic Test Accuracy Working Group. Systematic reviews of diagnostic test accuracy. Ann Intern Med 2008;149:889-97. doi:10.7326/00034819-149-12-200812160-00008

24 Sampson M, Shojania KG, McGowan J, et al. Surveillance search techniques identified the need to update systematic reviews. / Clin Epidemiol 2008;61:755-62. doi:10.1016/j.jclinepi.2007.10.003

25 Czosnyka M, Matta BF, Smielewski P, Kirkpatrick PI, Pickard JD. Cerebral perfusion pressure in head-injured patients: a noninvasive assessment using transcranial Doppler ultrasonography. J Neurosurg 1998;88:802-8. doi:10.3171/jns.1998.88.5.0802

26 Schmidt B, Klingelhöfer J, Schwarze JJ, Sander D, Wittich I. Noninvasive prediction of intracranial pressure curves using transcranial Doppler ultrasonography and blood pressure curves. Stroke 1997:28:2465-72. doi:10.1161/01.STR.28.12.2465

27 Whiting PF, Rutjes AW, Westwood ME, et al, QUADAS-2 Group. QUADAS-2: a revised tool for the quality assessment of diagnostic accuracy studies. Ann Intern Med 2011:155:529-36. doi:10.7326/0003-4819-155-8-201110180-00009

28 Rutter CM, Gatsonis CA. A hierarchical regression approach to meta-analysis of diagnostic test accuracy evaluations. Stat Med 2001:20:2865-84 doi:10.1002/sim 942

29 Takwoingi Y, Deeks JJ. MetaDAS: a SAS macro for meta-analysis of diagnostic accuracy studies. User Guide Version 1.3., Released 30 July 2010.

30 DerSimonian R, Laird N. Meta-analysis in clinical trials. Control Clin Trials 1986;7:177-88. doi:10.1016/0197-2456(86)90046-2 
31 Wallace BC, Dahabreh DA, Trikalinos TA, et al. Closing the gap between methodologists and end-users: $R$ as a computational backend. J Stat Softw 2012;49:1-15. doi:10.18637/jss.v049.i05

32 Balshem $\mathrm{H}$, Helfand M, Schünemann HJ, et al. GRADE guidelines: 3. Rating the quality of evidence. / Clin Epidemiol 2011;64:401-6. doi:10.1016/i.jclinepi.2010.07.015

33 Brozek JL, Akl EA, Jaeschke R, et al, GRADE Working Group. Grading quality of evidence and strength of recommendations in clinical practice guidelines: Part 2 of 3 . The GRADE approach to grading quality of evidence about diagnostic tests and strategies. Allergy 2009;64:1109-16. doi:10.1111/j.13989995.2009.02083x

34 Badri S, Chen J, Barber J, et al. Mortality and long-term functional outcome associated with intracranial pressure after traumatic brain injury. Intensive Care Med 2012;38:1800-9. doi:10.1007/s00134012-2655-4

35 Cardim D, Schmidt B, Robba C, et al. Transcranial Doppler Monitoring of Intracranial Pressure Plateau Waves. Neurocrit Care 2017;26:330 8. doi:10.1007/s12028-016-0356-5

36 Colquhoun IR, Burrows EH. The prognostic significance of the third ventricle and basal cisterns in severe closed head injury. Clin Radiol 1989;40:13-6. doi:10.1016/S0009. 9260(89)80006-6

37 Donovan JP, Schafer DF, Shaw BWJr, Sorrell MF. Cerebral oedema and increased intracranial pressure in chronic liver disease. Lancet 1998:351:719-21 doi:10.1016/S0140-6736(97)07373-X

38 Frumin E, Schlang J, Wiechmann W, et al. Prospective analysis of single operator sonographic optic nerve sheath diameter measurement for diagnosis of elevated intracranial pressure. West J Emerg Med 2014;15:217-20. doi:10.5811/ westjem.2013.9.16191

39 Gallbraith S, Teasdale G. Predicting the need for operation in the patient with an occult traumatic intracranial hematoma. Neurosurg 1981;55:75-81. doi:10.3171/jns.1981.55.1.0075

40 Geeraerts T, Launey Y, Martin L, et al. Ultrasonography of the optic nerve sheath may be useful for detecting raised intracranial pressure after severe brain injury. Intensive Care Med 2007;33:1704-11. doi:10.1007/s00134-007-0797-6

41 Hamani C, Zanetti MV, Pinto FC, Andrade AF, Ciquini OJr, Marino RJr. Intraventricular pressure monitoring in patients with thalamic and ganglionic hemorrhages. Arq Neuropsiquiatr 2003;61(2b):376-80. doi:10.1590/S0004-282X2003000300010

42 Hara M, Kadowaki C, Shiogai T, Takeuchi K. Correlation between intracranial pressure (ICP) and changes in CT images of cerebral hemorrhage. Neurol Res 1998;20:225-30. doi:10.1080/01616412. 1998.11740510

43 Hayashi M, Kobayashi H, Fujii H, Yamamoto S. Ventricular size and isotope cisternography in patients with acute transient rises of intracranial pressure (plateau waves). J Neurosurg 1982;57:797803. doi:10.3171/jns.1982.57.6.0797

44 Heuer GG, Smith MJ, Elliott JP, Winn HR, LeRoux PD. Relationship between intracranial pressure and other clinical variables in patients with aneurysmal subarachnoid hemorrhage. I Neurosurg 2004;101:408-16. doi:10.3171/jns.2004.101.3.0408

45 Hukkelhoven CW, Steyerberg EW, Habbema JD, Maas AI. Admission of patients with severe and moderate traumatic brain injury to specialized ICU facilities: a search for triage criteria. Intensive Care Med 2005;31:799-806. doi:10.1007/s00134-005-2628-y

46 Jeon JP, Lee SU, Kim SE, et al. Correlation of optic nerve sheath diameter with directly measured intracranial pressure in Korean adults using bedside ultrasonography. PLOS One 2017;12:e0183170. doi:10.1371/journal.pone.0183170

47 Jeon SB, Park JC, Kwon SU, et al. Intracranial pressure soon after hemicraniectomy in malignant middle cerebral artery infarction. J Intensive Care Med 2018;33:310-6. doi:10.1177/0885066616675598

48 Kamel H, Hemphill JC3rd. Characteristics and sequelae of intracranial hypertension after intracerebral hemorrhage. Neurocrit Care 2012;17:172-6. doi:10.1007/s12028-012-9744-7

49 Kimberly HH, Shah S, Marill K, Noble V. Correlation of optic nerve sheath diameter with direct measurement of intracranial pressure. Acad Emerg Med 2008;15:201-4. doi:10.1111/j.1553 2712.2007.00031.x

50 Kramer AH, Deis N, Ruddell S, et al. Decompressive craniectomy in patients with traumatic brain injury: are the usual indications congruent with those evaluated in clinical trials?Neurocrit Care 2016;25:10-9. doi:10.1007/s12028-015-0232-8

51 Lee HC, Lee WJ, Dho YS, Cho WS, Kim YH, Park HP. Optic nerve sheath diameter based on preoperative brain computed tomography and intracranial pressure are positively correlated in adults with hydrocephalus. Clin Neurol Neurosurg 2018;167:31-5. doi:10.1016/j.clineuro.2018.02.012

52 Marshall LF, Barba D, Toole BM, Bowers SA. The oval pupil: clinical significance and relationship to intracranial hypertension. J Neurosurg 1983;58:566-8. doi:10.3171/jns.1983.58.4.0566
53 Miller JD, Becker DP, Ward JD, Sullivan HG, Adams WE, Rosner MJ. Significance of intracranial hypertension in severe head injury. J Neurosurg 1977:47:503-16. doi:10.3171/ins.1977.47.4.0503

54 Moretti R, Pizzi B, Cassini F, Vivaldi N. Reliability of optic nerve ultrasound for the evaluation of patients with spontaneous intracranial hemorrhage. Neurocrit Care 2009;11:406-10. doi:10.1007/s12028-009-9250-8

55 Nagel A, Graetz D, Schink T, et al. Relevance of intracranial hypertension for cerebral metabolism in aneurysmal subarachnoid hemorrhage. Clinical article. J Neurosurg 2009;111:94-101. doi:10.3171/2009.1.JNS08587

56 Narayan RK, Kishore PR, Becker DP, et al. Intracranial pressure: to monitor or not to monitor? A review of our experience with severe head injury. J Neurosurg 1982;56:650-9. doi:10.3171/ jns.1982.56.5.0650

57 Nirula R, Millar D, Greene T, et al. Decompressive craniectomy or medical management for refractory intracranial hypertension: an AAST-MIT propensity score analysis. I Trauma Acute Care Surg 2014;76:944-52, discussion 952-5. doi:10.1097/ TA.0000000000000194

58 Pace J, Parry N, Vogt K, et al. A clinical prediction model for raised intracranial pressure in patients with traumatic brain injuries. I Trauma Acute Care Surg 2018;85:380-6. doi:10.1097| TA.0000000000001965

59 Raffiz M, Abdullah JM. Optic nerve sheath diameter measurement: a means of detecting raised ICP in adult traumatic and nontraumatic neurosurgical patients. Am J Emerg Med 2017;35:150-3. doi:10.1016/j.ajem.2016.09.044

60 Rajajee V, Vanaman M, Fletcher JJ, Jacobs TL. Optic nerve ultrasound for the detection of raised intracranial pressure. Neurocrit Care 2011;15:506-15. doi:10.1007/s12028-011-9606-8

61 Rajajee V, Williamson CA, Fontana RJ, Courey AJ, Patil PG. Noninvasive intracranial pressure assessment in acute liver failure [correction in: Neurocrit Care 2018;29:530]. Neurocrit Care 2018;29:280-90. doi:10.1007/s12028-018-0540-x

62 Rasulo FA, Bertuetti R, Robba C, et al. The accuracy of transcranial Doppler in excluding intracranial hypertension following acute brain injury: a multicenter prospective pilot study. Crit Care 2017;21:44. doi:10.1186/s13054-017-1632-2

63 Robba C, Cardim D, Tajsic T, et al. Ultrasound non-invasive measurement of intracranial pressure in neurointensive care: A prospective observational study. PLoS Med 2017;14:e1002356. doi:10.1371/journal.pmed.1002356

64 Sadhu VK, Sampson J, Haar FL, Pinto RS, Handel SF. Correlation between computed tomography and intracranial pressure monitoring in acute head trauma patients. Radiology 1979;133:507-9. doi:10.1148/133.2.507

65 Selhorst JB, Gudeman SK, Butterworth JF4th, Harbison JW, Miller JD, Becker DP. Papilledema after acute head injury. Neurosurgery 1985;16:357-63. doi:10.1227/00006123198503000-00013

66 Soldatos T, Karakitsos D, Chatzimichail K, Papathanasiou M, Gouliamos A, Karabinis A. Optic nerve sonography in the diagnostic evaluation of adult brain injury. Crit Care 2008;12:R67. doi:10.1186/cc6897

67 Soliman I, Johnson GGRJ, Gillman LM, et al. New optic nerve sonography quality criteria in the diagnostic evaluation of traumatic brain injury. Crit Care Res Pract 2018;2018:3589762 doi:10.1155/2018/3589762

68 Soustiel JF, Sviri GE, Mahamid E, Shik V, Abeshaus S, Zaaroor M. Cerebral blood flow and metabolism following decompressive craniectomy for control of increased intracranial pressure. Neurosurgery 2010;67:65-72, discussion 72. doi:10.1227/01. NEU.0000370604.30037.F5

69 Tabaddor K, Danziger A, Wisoff HS. Estimation of intracranial pressure by CT scan in closed head trauma. Surg Neurol 1982;18:212-5. doi:10.1016/0090-3019(82)90395-0

70 Teasdale E, Cardoso E, Galbraith S, Teasdale G. CT scan in severe diffuse head injury: physiological and clinical correlations. J Neurol Neurosurg Psychiatry 1984:47:600-3. doi:10.1136/innp.47.6.600

71 Wettervik TS, Lenell S, Nyholm L, Howells T, Lewén A, Enblad P. Decompressive craniectomy in traumatic brain injury: usage and clinical outcome in a single centre. Acta Neurochir (Wien) 2018;160:229-37. doi:10.1007/s00701-017-3418-3

72 Zoerle T, Lombardo A, Colombo A, et al. Intracranial pressure after subarachnoid hemorrhage. Crit Care Med 2015;43:168-76. doi:10.1097/CCM.0000000000000670

73 Zweifel C, Czosnyka M, Carrera E, de Riva N, Pickard JD, Smielewski P. Reliability of the blood flow velocity pulsatility index for assessment of intracranial and cerebral perfusion pressures in head injured patients. Neurosurgery 2012;71:853-61. doi:10.1227/ NEU.0b013e3182675b42

74 Marshall LF, Marshall SB, Klauber MR, et al. The diagnosis of head injury requires a classification based on computed axial tomography. J Neurotrauma 1992;9(Suppl 1):S287-92. 
75 Chesnut RM, Temkin N, Carney N, et al, Global Neurotrauma Research Group. A trial of intracranial-pressure monitoring in traumatic brain injury. N Engl J Med 2012;367:2471-81. doi:10.1056/ NEJMoa1207363

76 Cremer OL, van Dijk GW, van Wensen E, et al. Effect of intracranial pressure monitoring and targeted intensive care on functional outcome after severe head injury. Crit Care Med 2005;33:2207-13. doi:10.1097/01.CCM.0000181300.99078.B5

77 Farahvar A, Gerber LM, Chiu YL, Carney N, Härtl R, Ghajar !. Increased mortality in patients with severe traumatic brain injury treated without intracranial pressure monitoring. J Neurosurg 2012;117:729-34. doi:10.3171/2012.7.JNS111816

78 Agrawal D, Raghavendran K, Schaubel DE, Mishra MC, Rajajee V. A Propensity Score Analysis of the Impact of Invasive Intracranial Pressure Monitoring on Outcomes after Severe Traumatic Brain Injury. J Neurotrauma 2016;33:853-8. doi:10.1089/neu.2015.4015

79 Chesnut R, Videtta W, Vespa P, Le Roux P, Participants in the International Multidisciplinary Consensus Conference on Multimodality Monitoring. Intracranial pressure monitoring: fundamental considerations and rationale for monitoring. Neurocrit Care 2014;21(suppl 2):S64-84. doi:10.1007/s12028-014-0048-y

80 Gottlieb M, Bailitz I. Does Mannitol Reduce Mortality From Traumatic Brain Injury?Ann Emerg Med 2016:67:83-5. doi:10.1016/j. annemergmed.2015.06.027

81 Ropper AH. Lateral displacement of the brain and level of consciousness in patients with an acute hemispheral mass. N Engl J Med 1986;314:953-8. doi:10.1056/NEJM198604103141504

82 Toutant SM, Klauber MR, Marshall LF, et al. Absent or compressed basal cisterns on first CT scan: ominous predictors of outcome in severe head injury. J Neurosurg 1984;61:691-4. doi:10.3171/ ins.1984.61.4.0691

83 Eisenberg HM, Gary HEJr, Aldrich EF, et al. Initial CT findings in 753 patients with severe head injury. A report from the NIH Traumatic Coma Data Bank. J Neurosurg 1990;73:688-98. doi:10.3171/ ins.1990.73.5.0688

84 Moretti R, Pizzi B. Ultrasonography of the optic nerve in neurocritically ill patients. Acta Anaesthesiol Scand 2011;55:644-52. doi:10.1111/j.1399-6576.2011.02432.x

85 Robba C, Santori G, Czosnyka M, et al. Optic nerve sheath diameter measured sonographically as non-invasive estimator of intracranial pressure: a systematic review and meta-analysis. Intensive Care Med 2018:44:1284-94 doi:10.1007/s00134-018-5305-7

86 Lavinio A, Menon DK. Intracranial pressure: why we monitor it, how to monitor it, what to do with the number and what's the future?Curr Opin Anaesthesiol 2011;24:117-23. doi:10.1097/ ACO.0b013e32834458c5

87 Le Roux P, Menon DK, Citerio G, et al, Neurocritical Care Society, European Society of Intensive Care Medicine. Consensus summary statement of the International Multidisciplinary Consensus Conference on Multimodality Monitoring in Neurocritical Care: a statement for healthcare professionals from the Neurocritical Care Society and the European Society of Intensive Care Medicine. Intensive Care Med 2014;40:1189-209. doi:10.1007/s00134-014 3369-6

Web appendix: Electronic appendix 